\title{
ПРОБЛЕМЫ РАЗГРАНИЧЕНИЯ ПРЕДМЕТОВ ВЕДЕНИЯ МЕЖДУ ФЕДЕРАЛЬНЫМ ЦЕНТРОМ И СУБЪЕКТАМИ
}

Аннотация: Актуальность исследования обусловлена потребностями конституционно-правового осмысления происходящих преобразований в области российского федерализма. Цель исследования продолжсть научньй анализ проблем и особенностей разграничения предметов ведения между федеральным центром и субъектами. Объектом исследования являются общественные отношения, складывающчеся в прочессе формирования и развития федеративньх отношений, основанных на разграничении предметов ведения и компетенции в современном российском демократическомгосударстве. Предметом исследования являются нормы конституционного права, посредством которых осуществляется разграничение предметов ведения и компетенции в правовой системе Российской Федерации. Задача исследования-определить место вопросов исключительного и совместного ведения федерации и ее субъектов в правовом обеспечении федеративных отношений. Методологической основой исследования служит общенаучный диалектический метод познания. При написании работь использовались нормативно-правовой, сравнительно-правовой и иные специальнье методьл научного познания. В статье также рассмотрены различные точки зрения по проблемам разграничения полномочий и ответственности между федеральным центром и субъектами, приведены примеры из законодательной практики Чеченской Республики, делается вывод, что тенденция к иентрализачиии публичной власти должна быть уравновешена другой тенденичей - децентрализащией публичной власти, выдвигается тезис об особой роли договоров.

Abstract: Topicality of the study is due to the need of the constitutional legal cognition of the changes in the sphere of Russian federalism. The goal of the study is to continue scientific analysis of the problems and specific features regarding distinguishing objects of competence between the federal center and constituent subjects. The object of studies includes social relations, which are formed in the process of formation and development of federal relations, which are based on distinguishing the objects of competence in the modern Russian democratic state. The object of studies involves the norms of constitutional law, by which the objects of competence are distinguished within the legal system of the Russian Federation. The goal of the study is to define place of the issues of exclusive and joint competence of the federation and its constituent subjects within the legal guarantees of federal relations. The methodological basis for the study is formed with the general scientific dialectic cognition method. When writing the article the author used normative legal, comparative legal, and other special methods of scientific cognition. The article also involves analysis of various points of view regarding distinguishing competences and responsibility between the federal center and the constituent subjects, including examples from the legislative practice of the Chechen Republic. The author made a conclusion that the tendency for the centralization of the public power, which should be balanced by the other tendencies - decentralization of the public power, establishing the thesis of the special role of contracts. Ключевые слова: предметы ведения, органы государственной власти, дуализм, устав, территория, компетенция, конституцฺия, федеральный закон, принции коопераџии, субъект Российской Федерации.

Keywords: objects of competence, state government bodies, dualism, charter, territory, competence, constitution, federal law, cooperation principle, constituent subject of the Russian Federation.

общим чертам федеративного устройства государства относятся: наличие двух уровней управления - федерального и регионального, имеющих свои органы власти и управления; наличие у каждого из этих уровней своих собственных компетенций и институтов; закрепление разграничения предметов ведения между уровнями публичной власти в федеральной Конституции.
В доктрине конституционного права выделяется два основных способа разграничения предметов ведения между федерацией и ее субъектами: дуализм и кооперация. Дуалистический способ базируется на идеи разделения государственной власти в федеративном государстве таким образом, чтобы оба уровня управления были независимыми друг от друга, то есть государственная власть строго разделена, и ни 
одна из сторон не вправе вмешиваться в прерогативу власти другой стороны. Другой способ конституционного разграничения предметов ведения федерации и ее субъектов - способ кооперации. Он предполагает взаимодействие различных уровней управления при решении определенного круга вопросов.

В основу российской модели разграничения предметов ведения положен принцип кооперации. ${ }^{1}$ Конституция России помимо исключительных предметов ведения Российской Федерации (ст.71) выделяет предметы совместного ведения Российской Федерации и ее субъектов (ст.72) и предметы ведения субъектов Российской Федерации (ст.73).

Часть 3 ст. 11 Конституции Российской Федерации определила два способа разграничения предметов ведения и полномочий между органами государственной власти Российской Федерации и органами государственной власти ее субъектов: конституционный и договорный.

И.А. Умнова отмечает, что конституционный способ содержит в себе определенные противоречия, сравним, например, п. «в» ст. 71 и п. «б» ст. 72. Согласно п. «а» ст. 71 Конституции Российской Федерации в ведении Федерации находится принятие и изменение Конституции России. Вместе с тем в соответствии со ст. 136 Конституции Российской Федерации поправки к главам 3-8 принимаются в порядке, предусмотренном для принятия федерального конституционного закона, и вступают в силу после их одобрения органами законодательной власти не менее чем двух третей субъектов Российской Федерации. Это означает, что данное полномочие не является предметом исключительного ведения Российской Федерации и в определенных, установленных самой же Конституцией случаях, относится к совместному ведению. ${ }^{2}$

В Конституции России также имеется несогласованность норм в вопросе о полномочиях субъектов Российской Федерации в сфере исключительных предметов ведения Российской Федерации. Часть 1 статьи 76 исключает принятие субъектами Российской Федерации законов по предметам ведения Российской Федерации, одновременно часть 5 статьи 76 допускает существование таких законов.

Еще в 2002 году Д.Н. Козак в своей статье, констатирует, что «предметы ведения в Конституции Российской

\footnotetext{
1 Чернобровкина Н.И. Конституционные основы российского федерализма курс лекций 04.06.2013 [Электронный ресурс]. URL: http:// sfedu.ru/pls/rsu/ unr-download.

${ }^{2}$ Умнова И.А. Совместная конституционная модель российского федерализма//Государство и право.1999, №11. С.5-7. [Электронный pecypc]. // https://www.google.ru.
}

Федерации не разграничены по характеру оказываемого воздействия на сферы правового регулирования и сферы государственного управления, в которых осуществляются полномочия органов государственной власти. ${ }^{3}$ Рассмотрим вопрос, касающийся территории Российской Федерации, согласно п. «б» ст.71 данный вопрос отнесен Конституцией к исключительному предмету ведения Российской Федерации. При толковании данного пункта возникает вопрос, что следует понимать под территорией Российской Федерации. В соответствии с частью 1 ст. 67 Конституции территория Российской Федерации включает в себя территории ее субъектов, внутренние воды и территориальное море, воздушное пространство над ними. Отсюда напрашивается вывод, что территориальный вопрос относится к совместному предмету ведения Российской Федерации и ее субъектов. Однако, в соответствии с частью 3 ст. 67 Конституции границы между субъектами Российской Федерации могут быть изменены с их взаимного согласия, данная норма также относится к территориальному вопросу. Следовательно, делаем вывод, что этот вопрос относится к исключительному предмету ведения субъекта Российской Федерации. Очевидно, что данные нормы Конституции Российской Федерации нуждаются в серьезной корректировке, чтобы исключить такие нестыковки. К примеру, 4 июня 1992 года Верховный Совет Российской Федерации своим законом образовал новый субъект в составе Российской Федерации - Ингушскую Республику, выделив ее из состава Чечено-Ингушской Республики. Административная граница между Чеченской Республикой и Республикой Ингушетия должна была определена в том виде, в котором она была на момент объединения двух автономных областей Чеченской и Ингушской в 1934 году (граница была установлена постановлением ВЦИК в 1929 году). Из-за известных событий в Чеченской Республике часть территории, которая до 1934 года принадлежала Чеченской области, отошла Республике Ингушетия. С 2000 года, с момента установления легитимной власти в Чеченской Республике, данный вопрос поднимался не раз, однако руководство Республики Ингушетия игнорирует этот вопрос. Правительством и Парламентом Чеченской Республики были направлены обращения на имя руководства страны о необходимости вмешательства федерального центра в решение вопроса об определении административной границы между Чеченской

\footnotetext{
${ }^{3}$ Козак Д.Н. Проблемы разграничения полномочий между федеральными органами государственной власти и органами государственной власти субъектов Российской Федерации // Журнал российского права. - 2002. - № 5. - С. 3-11.
} 
DOI: $10.7256 / 1811-9018.2014 .6 .12244$

При цитировании этой статьи сноска на доі обязательна

\section{Право и политика $6(174) \cdot 2014$}

Республикой и Республикой Ингушетия, но данный вопрос до сих пор остается открытым.

Конституционные нормы, закрепляющие разграничение предметов ведения и полномочий органов публичной власти, нуждаются в серьезной корректировке.

Однозначно стает вопрос о принятии федерального закона, касающийся разрешения споров между органами государственной власти субъектов Российской Федерации, который позволил бы повысить эффективность взаимодействия государственных структур субъектов Российской Федерации.

Многие субъекты Российской Федерации устанавливают в своих основных законах (конституциях и уставах) предметы совместного ведения, уже установленные Конституцией Российской Федерации. В качестве примера можно привести Конституцию Чеченской Республики (ст. 60). ${ }^{4}$ В таком дублировании положений федеральной Конституции в основных законах субъектов Российской Федерации нет никакой необходимости, если в них отсутствует конкретизация компетенции органов государственной власти субъектов Российской Федерации в рамках прав, предоставленных федеральным законодателем. Такие нормы конституций и уставов являются неприемлемыми и с точки зрения невмешательства в прерогативу федерального регулирования.

Часть 6 статьи 76 Конституции Российской Федерации определила, что в случае противоречия между федеральным законом и нормативным правовым актом субъекта Российской Федерации, изданным по вопросу исключительного предмета ведения субъекта Российской Федерации, действует нормативный правовой акт субъекта Российской Федерации. Однако говорить о том, что государственная власть субъекта Российской Федерации обладает верховенством над федеральной властью было бы необоснованно. Здесь необходимо отметить, что данная норма не согласуется с ч. 2 ст. 4 Конституции России, которая закрепляет, что Конституция и федеральные законы имеют верховенство на всей территории Российской Федерации. Поэтому, говоря о приоритете закона субъекта Российской Федерации, принятого по предметам исключительного ведения субъекта, необходимо уточнить, что такой закон должен соответствовать Конституции Российской Федерации.

Противоречивость конституционных норм, касающихся определенного круга предметов ведения,

${ }^{4}$ Конституция Чеченской Республики: Принята на референдуме 23 марта 2003 года (ред. от 01.11.2012) // СПС Консультант Регион. порождают проблемы в их трактовке, следовательно, и в законодательстве, призванном обеспечивать реализацию конституционных основ разграничения предметов ведения между федеральными и региональными органами государственной власти Российской Федерации.

Следует указать еще на одно противоречивое положение в Конституции России. Разграничив предметы ведения между Российской Федерацией и ее субъектами в ст. 71, 72, Конституция одновременно допускает их разграничение посредством федеральных законов и договоров между органами государственной власти Российской Федерации и субъектов Российской Федерации. Получается, что дополнительно должны разграничиваться уже разграниченные Конституцией предметы ведения. Как справедливо указывал В.Е. Чиркин, в данном случае «по существу речь идет о вмешательстве в сферу отношений, установленную Конституцией Российской Федерации, причем путем точного перечня... Путем специального закона о разграничении совместных предметов ведения мы пытаемся корректировать Конституцию с помощью обыкновенного федерального закона, что-то из сферы совместных полномочий оставить за федерацией, а что-то передать субъектам. Но на это Конституция не уполномочивает». ${ }^{5}$

Что касается договорной формы разграничения предметов ведения и полномочий, установленной Конституцией Российской Федерации (ч.3 ст. 11), то следует отметить, что ее аналогов в других федеративных государствах нет. Согласно Федеральному закону «Об общих принципах организации законодательных (представительных) и исполнительных органах государственной власти субъектов Российской Федерации», они названы договорами о разграничении полномочий, а не предметов ведения. Заключение таких договоров допускается только в исключительных случаях, если это обусловлено экономическими, географическими и иными особенностями субъектов Российской Федерацией, и в той мере, в которой указанными особенностями определено иное разграничение полномочий, чем это установлено федеральными законами. В договоре должен устанавливаться перечень полномочий федеральных органов государственной власти и органов государственной власти субъектов Российской Федерации, разграничение которых производится иначе, чем это установлено федеральными законами и законами субъекта Российской Федерации, должны определяться условия и порядок осуществления этих

\footnotetext{
5 Чиркин B.E. Предметы ведения федерации и ее субъектов: разграничение, сотрудничество, субсидиарность // Государство и право. - 2002. - № 5. - С. 5-12.
} 
полномочий, конкретные права и обязанности сторон, срок действия договора и порядок его продления, а также основания и порядок досрочного расторжения договора (ч.1 ст. 26.7). Проект договора представляется высшим должностным лицом субъекта Российской Федерации (руководителем высшего исполнительного органа государственной власти субъекта Российской Федерации) в законодательный (представительный) орган субъекта Российской Федерации для одобрения, которое осуществляется большинством голосов от установленного числа депутатов в форме постановления (ч.4 ст. 26.7). Договор подписывается Президентом Российской Федерации и высшим должностным лицом субъекта Российской Федерации (руководителем высшего исполнительного органа государственной власти субъекта Российской Федерации) и утверждается федеральным законом (ч.7 и 9 ст. 26.7). Таким образом, Федеральный закон «Об общих принципах организации законодательных (представительных) и исполнительных органах государственной власти субъектов Российской Федерации» приравнял договор о разграничении полномочий по юридической силе к федеральному закону. Договор может быть изменен, его действие может быть приостановлено только путем внесения в него изменений и дополнений в порядке, аналогичном порядку заключения и вступления в силу такого договора. Договор является временным, и срок его действия не может превышать десять лет (ч.10 ст.26.7). Досрочное прекращение договора (расторжение) возможно по взаимному согласию сторон или на основании решения суда о нарушении одной из сторон положений договора (ч. 11 ст.26.7).

Одни исследователи утверждают, что договоры «подправляют» положения федеральной конституции о совместных предметах ведения. По мнению Черепанова В.А. «необходимость в договорном процессе очевидна. Конституция и федеральный закон не могут учесть специфику субъектов, различающихся по численности, национальному составу, социально-экономическому и геополитическому положению. Договоры как раз и позволяют учесть эти особенности и осуществлять правовое регулирование федеративных отношений во всем многообразии регионов России». ${ }^{6}$

Другие исследователи отмечают негативную роль договоров. Новоселова-Чурсина Е.С. утверждает, что «договоры являются тем фактором, который разрушает целостность и определенность конституционно-право-

\footnotetext{
6 Черепанов В.А. Конституционное право России. Курс лекций:
} учебное пособие...Ставрополь: АГРУС, 2012. - С. - 254. вой системы разграничения предметов ведения между Федерацией и ее субъектами. Подписание двусторонних договоров и соглашений противоречит принципу государственного суверенитета Российской Федерации. Оно приводит к распылению единой воли Федерации и ее составных частей, изначально выраженной в согласованном сторонами документе - Конституции и федеральном законе». ${ }^{7}$

По сути, на настоящий момент большинство договоров заключено не столько потому, чтобы учесть специфику субъектов Российской Федерации, сколько для того, чтобы заменить или дополнить нормы Конституции Российской Федерации и федерального законодательства. Таким образом, стоит согласиться с теми конституционалистами, которые считают, что договор является не самой удачной формой разграничения компетенции между Российской Федерацией и ее субъектами.

Каждый из предметов совместного ведения Российской Федерации и ее субъектов, перечисленных в части 1 ст. 72 Конституции, подлежит конкретизации в федеральных законах, договорах о разграничении полномочий и соглашениях, а также в законах субъектов Российской Федерации.

Например, в соответствии с п. «о» части 1 ст. 72 Конституции субъекты Российской Федерации могут быть самостоятельными участниками международных и внешнеэкономических отношений, если это не противоречит Конституции Российской Федерации и федеральным законам. В Конституции Чеченской Республики имеется положение о праве республики осуществлять международные и внешнеэкономические связи, выполнение международных договоров Российской Федерации (п.14 ст. 60).

На федеральном уровне принят Федеральный закон «Об общих принципах организации законодательных (представительных) и исполнительных органов государственной власти субъектов Российской Федерации» ${ }^{8}$, на основе общих принципов, закрепленных данным федеральным законом, в Чеченской Республике приняты законы, определяющие организацию государственной власти в Чеченской Республике: Конституция

\footnotetext{
${ }^{7}$ Новоселова-Чурсина Е.С. Принципы федерализма в решениях Конституционного Суда Российской Федерации. «Конституционное и муниципальное право», 2007, № 3 // www.lawlibrary.ru.

${ }^{8}$ Об общих принципах организации законодательных (представительных) и исполнительных органов государственной власти субъектов Российской Федерации: Федеральный закон от 6 октября 1999 года № 184-Ф3 (ред. от 07.06. 2013г.) // СПС КонсультантПлюс.
} 
DOI: $10.7256 / 1811-9018.2014 .6 .12244$

При цитировании этой статьи сноска на dоі обязательна

\section{Право и политика $6(174) \cdot 2014$}

Чеченской Республики; ${ }^{9}$ Конституционный закон Чеченской Республики «О Парламенте Чеченской Республики»; ${ }^{10}$ Конституционный закон Чеченской Республики «О системе органов исполнительной власти Чеченской Республики». ${ }^{11}$

В соответствии с общими принципами, закрепленными Федеральным законом «Об общих принципах организации местного самоуправления в Российской Федерации», принят Закон Чеченской Республики «О местном самоуправлении в Чеченской Республике», который определяет организацию местного самоуправления в Чеченской Республике. ${ }^{12}$

На основе принципов судоустройства, установленных Федеральным конституционным законом «О судебной системе Российской Федерации», приняты Конституционный закон «О Конституционном Суде Чеченской Республики» ${ }^{13}$ и назначены судьи Конституционного Суда Чеченской Республики, а также принят Закон Чеченской Республики «О мировых судьях Чеченской Республики» ${ }^{14}$ и назначены 66 мировых судей Чеченской Республики.

В соответствии с общими принципами налогообложения, установленными Налоговым кодексом Российской Федерации, в Чеченской Республике в рамках региональной компетенции приняты республиканские законы, касающиеся особенностей обложения региональными налогами..$^{15}$

Стоит согласиться с исследователями, которые утверждают, что деятельность региональных парламентов в области совместной компетенции постепенно транс-

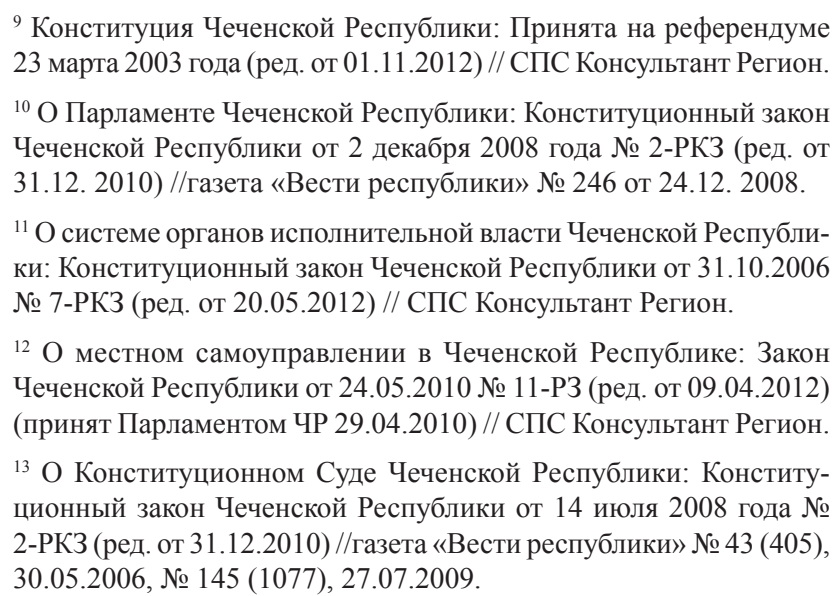

${ }^{14} \mathrm{O}$ мировых судьях Чеченской Республики: Закон Чеченской Республики 27 сентября 2006 года № 28- Р3 (ред. от 22.05.2008) //газета «Вести республики» № 60, 08.05. 2007, № 106 (788), 06.06.2008.

${ }^{15}$ О применении упрощенной системы налогообложения на основе патента в Чеченской Республике: Закон Чеченской Республики от 11.04.2008 № 10-Р3 (ред. от 25.03.2009) // СПС Консультант Регион. формируется в правовое наполнение так называемых «рамочных законов», принятых федеральным центром. ${ }^{16}$

Конституция Российской Федерации не закрепила предметы ведения субъектов Российской Федерации в явной форме, а обозначила их по остаточному принципу. Собственное ведение субъектов Российской Федерации закреплено в ст. 73 Конституции Российской Федерации на основе способа децентрализации. В этих пределах они осуществляют собственное правовое регулирование, включая принятие законов и иных нормативных правовых актов (ч.4 ст.76).

К примеру, Законом Чеченской Республики: утверждаются бюджет Чеченской Республики и отчет о его исполнении, представленные Главой Чеченской Республики; устанавливаются в соответствии с Конституцией Чеченской Республики основы организации и деятельности Парламента Чеченской Республики; в пределах полномочий, определенных федеральным законом, устанавливается порядок проведения выборов в органы местного самоуправления на территории Чеченской Республики; утверждаются программы социально-экономического развития Чеченской Республики, представленные Главой Чеченской Республики; устанавливаются налоги и сборы, установление которых отнесено федеральным законом к ведению Чеченской Республики, а также порядок их взимания; утверждаются бюджеты территориальных государственных внебюджетных фондов Чеченской Республики и отчеты об их исполнении; устанавливается порядок управления и распоряжения собственностью Чеченской Республики, в том числе долями (паями, акциями) Чеченской Республики в капиталах хозяйственных обществ, товариществ и предприятий иных организационно-правовых форм; утверждаются заключение и расторжение договоров Чеченской Республики; устанавливается порядок назначения и проведения референдума Чеченской Республики; устанавливаются порядок проведения выборов в Парламент Чеченской Республики, порядок проведения выборов Главы Чеченской Республики и порядок отзыва Главы Чеченской Республики; устанавливается административно-территориальное устройство Чеченской Республики и порядок его изменения; устанавливается система исполнительных органов государственной власти Чеченской Республики; устанавливаются полномочия, порядок назначения на должность и освобождения от должности Уполномоченного по правам человека в Чеченской

\footnotetext{
${ }_{16}$ Чирнинов А.М. Конституционно-правовые механизмы разграничения предметов ведения и полномочий // Современные научные исследования и инновации. - 2012. - № 5 [Электронный ресурс]. URL: http://web.snauka.ru/issues.
} 
Республике; регулируются иные вопросы, относящиеся в соответствии с Конституцией Российской Федерации, федеральными законами, Конституцией Чеченской Республики и законами Чеченской Республики к ведению и полномочиям Чеченской Республики (ст. 84 Конституции Чеченской Республики).

Как уже неоднократно подчеркивалось, что действующая модель разграничения предметов ведения по объему концентрации прав Российской Федерации и правил их изменения тяготеет к централизованной системе власти и управления. Как отметил В.А. Черепанов «подавляющая часть совместного правового поля отдана в компетенцию федеральной власти, оставшийся кусочек региональной компетенции в любой момент может быть перераспределен». ${ }^{17}$

Тенденция к централизации публичной власти должна быть уравновешена другой тенденцией - децентрализацией публичной власти и в этой связи думаю, стоит согласиться с мнением М.Х. Фарукшина «в федерациях, построенных по национально-территориальному принципу, степень децентрализации должна была быть, как правило, более значительной. Однако при всем том, думается, не принцип, лежащий в основе построения федерации, является определяющим для соотношения тенденций к централизации или децентрализации. В этом плане ведущее значение, на наш взгляд, приобретает сфера управления, в которой задействованы, в первую очередь, федеральные власти или органы государственной власти субъектов федерации. В тех сферах, которые в интересах федерации в целом должны быть отнесены к исключительной компетенции федеральных органов власти (например, оборона, внешняя политика, валютная система и др.), конечно, преобладает централизация. Управление же в сферах, в которых могут прекрасно разобраться сами субъекты федерации без излишнего вмешательства федерального центра, должно быть естественным образом децентрализовано. Учет обеих тенденций: централизации и децентрализации - необходимое условие рационального разграничения предметов ведения и полномочий между федерацией и ее субъектами». ${ }^{18}$

Курс на децентрализацию полномочий между уровнями публичной власти в пользу субъектов Российской Федерации и местного самоуправления был провозглашен Экс-президентом России Д.А. Медведевым еще

17 Черепанов B.A. Конституционное право России. Курс лекций: учебное пособие...Ставрополь: АГРУС, 2012. - С. - 249.

18 Фарукшин М.X. Современный федерализм: российский и зарубежный опыт. // Изд-во Казанского университета, 1998. С-35. [Электронный ресурс] http: // do.gendocs.ru. в 2011 году на Санкт-Петербургском международном форуме. Созданные его решением рабочие группы по правовым вопросам перераспределения полномочий между федеральными органами исполнительной власти, органами исполнительной власти субъектов Российской Федерации и органами местного самоуправления должны были подготовить предложения, предусматривающие, в том числе, меры по увеличению доли доходов региональных и местных бюджетов в структуре консолидированного бюджета Российской Федерации, соответствующие новому распределению полномочий. ${ }^{19}$ Движение в этом направлении обозначилось, но результаты пока не видны.

\section{Библиография:}

1. Козак Д.Н. Проблемы разграничения полномочий между федеральными органами государственной власти и органами государственной власти субъектов Российской Федерации // Журнал российского права. - 2002. - № 5. - С. 3-11.

2. Новоселова-Чурсина Е.С. Принципы федерализма в решениях Конституционного Суда Российской Федерации. «Конституционное и муниципальное право», 2007, № 3 // www.lawlibrary.ru.

3. Соколов И.А. Конституционное право Российской Федерации: Учебное пособие. - М.: МГИУ, 2010. $-260 \mathrm{c}$.

4. Фарукшин М.Х. Современный федерализм: российский и зарубежный опыт. // Изд-во Казанского университета, 1998. С-35. [Электронный ресурс] http: // do.gendocs.ru.

5. Чернобровкина Н.И. Конституционные основы российского федерализма курс лекций 04.06.2013 [Электронный ресурc]. URL: http:// sfedu.ru/pls/rsu/ unr-download.

6. Чирнинов А.М. Конституционно-правовые механизмы разграничения предметов ведения и полномочий // Современные научные исследования и инновации. - 2012. - № 5 [Электронный ресурс]. URL: http://web.snauka.ru/issues.

7. Чиркин В.Е. Предметы ведения федерации и ее субъектов: разграничение, сотрудничество, субсидиарность // Государство и право. - 2002. - № 5. - С. 5-12.

8. Жолобова О.А.. Развитие теории федерализма в рамках социально-философского и институцио-

\footnotetext{
${ }^{19}$ Бюджетное послание Президента РФ Д.А. Медведева от 29 июня 2011 года «О бюджетной политике в 2012 - 2014 годах» //www/garant/ru.
} 
DOI: $10.7256 / 1811-9018.2014 .6 .12244$

При цитировании этой статьи сноска на dоі обязательна

\section{Право и политика $6(174) \cdot 2014$}

нального подходов на Западе // Международные отношения. - 2013. - № 3. - C. 104-107. DOI: 10.7256/2305-560Х.2013.3.8982

9. М.Н. Федорец. Особенности становления и развития американского федерализма // Политика и Общество. - 2013. - № 4. - C. 104-107. DOI: 10.7256/1812-8696.2013.04.3

10. Бунчук В.Л.. Механизмы реализации региональной политики России в контексте эволюции федеративных отношений // Международные отношения. - 2013. - № 2. - C. 104-107. DOI: 10.7256/2305560X.2013.02.6

11. В.Л. Бунчук. Становление и эволюция федеративной модели в современной России // Национальная безопасность / nota bene. - 2013. - № 1. - C. 104-107. DOI: $10.7256 / 2073-8560.2013 .01 .8$

12. А.В. Безруков. Роль Президента России в механизме реализации конституционных принципов федерализма, единства государственной власти и разделения властей // Политика и Общество. - 2013. - № 3. - С. 104-107. DOI: 10.7256/1812-8696.2013.03.2

13. Умнова И.А. Совместная конституционная модель российского федерализма//Государство и право.1999, №11. С.5-7. [Электронный ресурс]. // https://www.google.ru.

14. Р.К. Искужин. Методологический кризис российского федерализма // Политика и Общество. - 2013. - № 1. - С. 104-107. DOI: 10.7256/1812-8696.2013.01.2

15. Черепанов В.А. Конституционное право России. Курс лекций: учебное пособие... Ставрополь: АГРУС, 2012. - 448 с.

16. С.В. Нарутто. Понятие и границы территории субъекта Российской Федерации // Национальная безопасность / nota bene. - 2012. - № 6. - С. 104-107

17. Никифорова А.В. Правовые позиции органов конституционной юстиции по вопросам территориальной организации местного самоуправления // NB: Вопросы права и политики. - 2012. - 1. - C. 69 - 91. URL: http://www.e-notabene.ru/ 1r/article_29.html

18. А.М. Цалиев О расширении роли субъектов Российской Федерации во внутренней государственной политике // Право и политика. - 2013. - 1 . - C. 6 - 12. DOI: 10.7256/1811-9018.2013.01.1.

\section{References (transliteration):}

1. Kozak D.N. Problemy razgranicheniya polnomochii mezhdu federal'nymi organami gosudarstvennoi vlasti i organami gosudarstvennoi vlasti sub"'ektov Rossiiskoi Federatsii // Zhurnal rossiiskogo prava. 2002. - № 5. - S. 3-11.

2. Novoselova-Chursina E.S. Printsipy federalizma v resheniyakh Konstitutsionnogo Suda Rossiiskoi Federatsii. «Konstitutsionnoe i munitsipal'noe pravo», 2007, № 3 // www.lawlibrary.ru.

3. Sokolov I.A. Konstitutsionnoe pravo Rossiiskoi Federatsii: Uchebnoe posobie. - M.: MGIU, 2010. 260s.

4. Farukshin M.Kh. Sovremennyi federalizm: rossiiskii i zarubezhnyi opyt. // Izd-vo Kazanskogo universiteta, 1998. S-35. [Elektronnyi resurs] http: // do.gendocs.ru.

5. Chernobrovkina N.I. Konstitutsionnye osnovy rossiiskogo federalizma kurs lektsii 04.06.2013 [Elektronnyi resurs]. URL: http:// sfedu.ru/pls/rsu/ unr-download.

6. Chirninov A.M. Konstitutsionno-pravovye mekhanizmy razgranicheniya predmetov vedeniya i polnomochii // Sovremennye nauchnye issledovaniya $\mathrm{i}$ innovatsii. - 2012. - № 5 [Elektronnyi resurs]. URL: http://web. snauka.ru/issues.

7. Chirkin V.E. Predmety vedeniya federatsii i ee sub"ektov: razgranichenie, sotrudnichestvo, subsidiarnost' // Gosudarstvo i pravo. - 2002. - № 5. - S. 5-12.

8. Zholobova O.A.. Razvitie teorii federalizma v ramkakh sotsial'no-filosofskogo i institutsional'nogo podkhodov na Zapade // Mezhdunarodnye otnosheniya. - 2013. - № 3. - S. 104-107. DOI: 10.7256/2305560X.2013.3.8982

9. M.N. Fedorets. Osobennosti stanovleniya i razvitiya amerikanskogo federalizma // Politika i Obshchestvo. - 2013. - № 4. - S. 104-107. DOI: 10.7256/18128696.2013.04.3

10. Bunchuk V.L.. Mekhanizmy realizatsii regional'noi politiki Rossii v kontekste evolyutsii federativnykh otnoshenii // Mezhdunarodnye otnosheniya. - 2013. № 2. - S. 104-107. DOI: 10.7256/2305-560X.2013.02.6

11. V.L. Bunchuk. Stanovlenie i evolyutsiya federativnoi modeli v sovremennoi Rossii // Natsional'naya bezopasnost' / nota bene. - 2013. - № 1. - S. 104-107. DOI: 10.7256/2073-8560.2013.01.8

12. A.V. Bezrukov. Rol' Prezidenta Rossii v mekhanizme realizatsii konstitutsionnykh printsipov federalizma, edinstva gosudarstvennoi vlasti i razdeleniya vlastei // Politika i Obshchestvo. - 2013. - № 3. - S. 104-107. DOI: $10.7256 / 1812-8696.2013 .03 .2$

13. Umnova I.A. Sovmestnaya konstitutsionnaya model' rossiiskogo federalizma//Gosudarstvo i pravo.1999, №11. S.5-7. [Elektronnyi resurs]. // https://www. google.ru. 
14. R.K. Iskuzhin. Metodologicheskii krizis rossiiskogo federalizma // Politika i Obshchestvo. - 2013. - № 1. - S. 104-107. DOI: 10.7256/1812-8696.2013.01.2

15. Cherepanov V.A. Konstitutsionnoe pravo Rossii. Kurs lektsii: uchebnoe posobie...Stavropol': AGRUS, 2012. $-448 \mathrm{~s}$.

16. S.V. Narutto. Ponyatie i granitsy territorii sub"ekta Rossiiskoi Federatsii // Natsional'naya bezopasnost' / nota bene. - 2012. - № 6. - S. 104-107
17. Nikiforova A.V. Pravovye pozitsii organov konstitutsionnoi yustitsii po voprosam territorial'noi organizatsii mestnogo samoupravleniya // NB: Voprosy prava i politiki. - 2012. - 1. - C. 69 - 91. URL: http://www.enotabene.ru/lr/article_29.html

18. A.M. Tsaliev O rasshirenii roli sub"ektov Rossiiskoi Federatsii vo vnutrennei gosudarstvennoi politike // Pravo i politika. - 2013. - 1. - C. 6 - 12. DOI: 10.7256/1811-9018.2013.01.1. 